\title{
Graphene Synthesis Using a CVD Reactor and a Discontinuous Feed of Gas Precursor at Atmospheric Pressure
}

\author{
A. Moreno-Bárcenas, ${ }^{1}$ J. F. Perez-Robles, ${ }^{1}$ Y. V. Vorobiev, ${ }^{1}$ N. Ornelas-Soto, ${ }^{2}$ \\ A. Mexicano, ${ }^{3}$ and A. G. García $\mathbb{1}^{4}$ \\ ${ }^{1}$ Centro de Investigación y de Estudios Avanzados del Instituto Politécnico Nacional, Real de Juriquilla, \\ 76230 Santiago de Querétaro, QRO, Mexico \\ ${ }^{2}$ Laboratorio de Nanotecnología Ambiental, Tecnológico de Monterrey, Escuela de Ingeniería y Ciencias, \\ Ave. Eugenio Garza Sada 2501, 64849 Monterrey, NL, Mexico \\ ${ }^{3}$ Instituto Tecnológico de Cd. Victoria, Boulevard Emilio Portes Gil No. 1301, Pte. A.P. 175, 87010 Ciudad Victoria, TAMPS, Mexico \\ ${ }^{4}$ Laboratorio de Síntesis y Modificación de Nanoestructuras y Materiales Bidimensionales, \\ Centro de Investigación en Materiales Avanzados S.C., Alianza Norte No. 202, Parque PIIT, 66628 Apodaca, NL, Mexico
}

Correspondence should be addressed to A. G. García; alejandra.garcia@cimav.edu.mx

Received 18 October 2017; Revised 26 January 2018; Accepted 30 January 2018; Published 18 March 2018

Academic Editor: Victor M. Castaño

Copyright (C) 2018 A. Moreno-Bárcenas et al. This is an open access article distributed under the Creative Commons Attribution License, which permits unrestricted use, distribution, and reproduction in any medium, provided the original work is properly cited.

\begin{abstract}
The present work shows a new method in order to cost-effectively achieve the synthesis of graphene by Chemical Vapor Deposition (CVD). Unlike most usual processes, where precursors such as argon, $\mathrm{H}_{2}, \mathrm{CH}_{4}$, and high purity copper foil are used, the proposed method has replaced the previous ones by $\mathrm{N}_{2}, \mathrm{~N}_{2}(90 \%): \mathrm{H}_{2}(10 \%), \mathrm{C}_{2} \mathrm{H}_{2}$, and electrolytic copper (technical grade) since the use of industrialized precursors helps reduce production costs. On the other hand, the process was modified from a continuous flow system with vacuum to a discontinuous one at atmospheric pressure, eliminating the use of vacuum pump. In addition, this modification optimized the consumption of gases, which reduced the waste and the emission of pollutant gases into the atmosphere. Graphene films were grown under different gas flowrates and temperatures. Then, the obtained material was characterized by TEM, Raman spectroscopy, and AFM, confirming the presence of few graphene layers. In brief, the growth time was reduced to six minutes with acetylene as a carbon precursor at $1000^{\circ} \mathrm{C}$ and at atmospheric pressure, with a flow rate of $30 \mathrm{sccm}$. Finally, the reported conditions can be used for the synthesis of good quality graphene films in industrial applications.
\end{abstract}

\section{Introduction}

Graphene is a two-dimensional material with $\mathrm{sp}^{2}$ hybridization and carbon atoms in a honeycomb arrangement $[1$, 2]. Nevertheless, it was not until 2004, after its isolation by mechanical exfoliation, that electric properties of a monolayer were published [3], followed by many other studies that showed extremely interesting properties, such as electronic mobility in room temperature higher than $2.105 \mathrm{~cm}^{2} \mathrm{~V}^{-1} \mathrm{~S}^{-1}$, Young's Modulus of $1 \mathrm{TPa}$, thermal conductivity above $3000 \mathrm{WmK}^{-1}, 2.3 \%$ of optical absorption, and the capacity to be functionalized by a wide range of organic groups [4-6]. Hence, graphene is a material with a broad range of applications from mechanical, electrical, and optical applications to medical ones [5, 7]. Several methods have been used to prepare graphene, including graphite micromechanical exfoliation, epitaxial growth over $\mathrm{SiC}$, graphite oxide reduction, and CVD [8] with the unique purpose to obtain large areas and more production $[9,10]$.

Therefore considering its high productivity, CVD is one of the most promising processes to grow high quality graphene in large areas [11-13]. Accordingly, in recent years a considerable effort has been done to optimize the process, improve the kind of substrate, and control graphene growth $[12,14]$.

In initial experiments to form graphene, CVD systems with methane as the carbon precursor and hydrogen as a balancing gas were used and are still commonly used today. Thereafter, atmospheric pressure CVD (AP-CVD) or other 
TABLE 1: Overview of CVD processes synthesis.

\begin{tabular}{|c|c|c|c|c|c|c|c|c|c|}
\hline \multirow[b]{2}{*}{ Substrate } & \multicolumn{2}{|c|}{ Annealing } & \multicolumn{4}{|c|}{ Growth conditions } & \multirow{2}{*}{$\begin{array}{c}\text { Temperature } \\
\left({ }^{\circ} \mathrm{C}\right)\end{array}$} & \multirow{2}{*}{$\begin{array}{l}\text { Total time } \\
\quad(\min )\end{array}$} & \multirow[b]{2}{*}{ Ref. } \\
\hline & Gas & $\begin{array}{l}\text { Time } \\
(\mathrm{min})\end{array}$ & Precursor & $\begin{array}{l}\text { Flowrate } \\
(\mathrm{sccm})^{* *}\end{array}$ & Gas ratio & $\begin{array}{c}\text { Pressure } \\
\text { (torr) }\end{array}$ & & & \\
\hline $\mathrm{Cu}-\mathrm{p}$ & $\mathrm{H}_{2} / \mathrm{Ar}$ & & $\mathrm{CH}_{4}$ & 5 & 1 & 700 & 1045 & $>143$ & [26] \\
\hline $\mathrm{Cu}-\mathrm{p}$ & $\mathrm{H}_{2} / \mathrm{Ar}$ & 30 & $\mathrm{CH}_{4} / \mathrm{Ar}$ & 15 & $1: 1000$ & --- & 1050 & 125 & [27] \\
\hline $\mathrm{Cu}-\mathrm{p}$ & $\mathrm{H}_{2}$ & 30 & $\mathrm{CH}_{4}$ & --- & 1 & 0.15 & 950 & 1620 & [20] \\
\hline $\mathrm{Cu}(111)$ & $\mathrm{H}_{2}$ & 5 & $\mathrm{CH}_{4}$ & 35 & 1 & $3.9 \times 10^{-2}$ & 1000 & 60 & {$[21]$} \\
\hline $\mathrm{Cu}-\mathrm{p}$ & $\mathrm{H}_{2} / \mathrm{Ar}$ & $60-180$ & $\mathrm{CH}_{4}$ & --- & $1: 1000$ & & 1000 & 180 & [28] \\
\hline $\mathrm{Cu}-\mathrm{p}$ & $\mathrm{H}_{2}$ & 20 & $\mathrm{CH}_{4} / \mathrm{H}_{2}$ & 50 & $1: 1$ & 0.35 & 1000 & 60 & [29] \\
\hline $\mathrm{Cu}-\mathrm{p}$ & $\mathrm{H}_{2}$ & & $\mathrm{CH}_{4} / \mathrm{H}_{2}$ & $5-20$ & $2: 1$ & 0.01 & 1000 & 180 & {$[30]$} \\
\hline $\mathrm{Cu}-\mathrm{p}$ & $\mathrm{H}_{2} / \mathrm{Ar}$ & 10 & $\mathrm{CH}_{4} / \mathrm{H}_{2}$ & $1-8$ & $1: 20$ & --- & 1000 & & {$[31]$} \\
\hline $\mathrm{Cu}-\mathrm{p}$ & $\mathrm{H}_{2} / \mathrm{Ar}$ & 5 & $\mathrm{CH}_{4}$ & ---- & 1 & 10 & 1000 & 21 & [27] \\
\hline $\mathrm{Cu}-\mathrm{p}$ & $\mathrm{H}_{2} / \mathrm{Ar}$ & 30 & $\mathrm{CH}_{4} / \mathrm{Ar}$ & 40 & $1: 9$ & ---- & 950 & 160 & {$[32]$} \\
\hline $\mathrm{Ni}$ & $\mathrm{H}_{2}$ & 20 & $\mathrm{C}_{2} \mathrm{H}_{2} / \mathrm{H}_{2}$ & $6-36$ & $2: 1$ & 0.99 & 900 & 60 & [33] \\
\hline $\mathrm{Cu}-\mathrm{p}$ & $\mathrm{H}_{2} / \mathrm{Ar}$ & 20 & $\mathrm{C}_{2} \mathrm{H}_{2} / \mathrm{Ar}$ & $1-12$ & $12: 1000$ & --- & 1000 & 150 & [34] \\
\hline $\mathrm{Cu}-\mathrm{p}$ & $\mathrm{H}_{2}$ & 40 & $\mathrm{C}_{2} \mathrm{H}_{2} / \mathrm{H}_{2}$ & 0.28 & $1: 280$ & 0.8 & 1035 & 95 & [35] \\
\hline $\mathrm{Cu}-\mathrm{p}$ & $\mathrm{H}_{2}$ & 60 & $\mathrm{C}_{2} \mathrm{H}_{2}$ & --- & 1 & --- & 900 & 720 & {$[36]$} \\
\hline $\begin{array}{l}\mathrm{Cu}-\mathrm{p} \text { industrial } \\
\text { grade }\end{array}$ & $\mathrm{N}_{2}$ & 20 & $\mathrm{C}_{2} \mathrm{H}_{2}$ & 30 & 1 & 760 & 1000 & 66 & * \\
\hline
\end{tabular}

$\mathrm{Cu}$-p: copper polycrystalline laboratory grade. ${ }^{*}$ This work. ${ }^{* *}$ Standard cubic centimeter per minute. Note. In this table the time cooling and heating is not considered.

carbon feedstocks have been explored (other gaseous hydrocarbons or carbon containing liquid or solid precursors) $[15,16]$. Hydrogen is almost always used to achieve a better control in the synthesis of graphene on $\mathrm{Cu}$. In industry, due to safety and cost issues, the use of pure hydrogen may not be preferred. Although processes using diluted hydrogen and methane have been developed, it should be noted that, in practice, these gases invariably contain trace amounts of oxidative impurities, which may have a significant effect on graphene growth [17].

At the same time, a deeper understanding has been acquired for each role in the synthesis stages [10, 13, 18, 19]. And two main challenges have been identified concerning graphene quality. First, substrates can lose their catalytic activity during permanence time inside the reactor, a process known as "cooking." The second factor is related to the high temperatures and long growth times needed when monocrystalline cooper (111) is used as a substrate. An important challenge in graphene synthesis is to obtain high production volumes with high structural quality and visualize a methodology for future application on an industrial scale. Even so, the reported experiments still contemplate long synthesis times of up to $27 \mathrm{hrs}$ at continuous gas flowrates [20] and expensive substrates [21] (Table 1). When the above variables are not taken into account, the performance and commercial attractiveness of this material could be decreased or limited [22].

The improvement of each of these aspects enables the control of graphene properties to satisfy the applicationoriented needs such as production specifications (e.g., cost, rate). Until now, the commercial use of graphene is still restricted by the lack of standardized techniques for production that guarantee high energy efficiency and high structural quality. The improvement of electronic devices depends strongly on the quality of the graphene obtained [23].

In this paper, a novel and fast CVD method for graphene synthesis is proposed in order to decrease dramatically the usage of gases in a batch process. In addition, $\mathrm{Cu}$ (technical grade) polycrystalline substrates are used instead of monocrystalline (111) or laboratory grade (reagent) decreasing the production costs about 80 percent when compared to traditional CVD processes. Finally, the proposed method allowed the production of graphene with a similar quality $\left(I_{2 \mathrm{D}} / I_{\mathrm{G}}>2\right)$ to that obtained by methods that require high vacuum and continuous gas flowrate $[24,25]$.

\section{Experimental}

2.1. Materials. Polycrystalline copper foils of quality electrolytic industrial (C-1100) with a size of $15 \times 30 \mathrm{~cm}$ and purity of $99.9 \% \mathrm{w} / \mathrm{w}$ were used as substrates. The copper was washed with plenty of acetone and cleaned with wipes to remove grease and dust. Acetylene gas was used as carbon precursor with $98 \%$ concentration. High purity nitrogen gas was used for getting a neutral atmosphere and a high purity $90: 10$ mixture of $\mathrm{N}_{2}: \mathrm{H}_{2}$ gases were used to obtain reducing conditions inside the reactor and before the graphene deposition. A conventional CVD reactor provided with an inverted compressor was used in order to facilitate the gas expulsion.

2.2. Growth Process. The studied parameters were temperature and flow rate of carbon precursor. In brief, a flow 


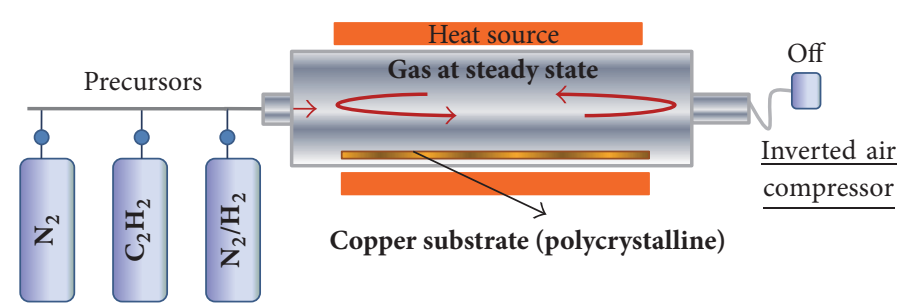

(a)

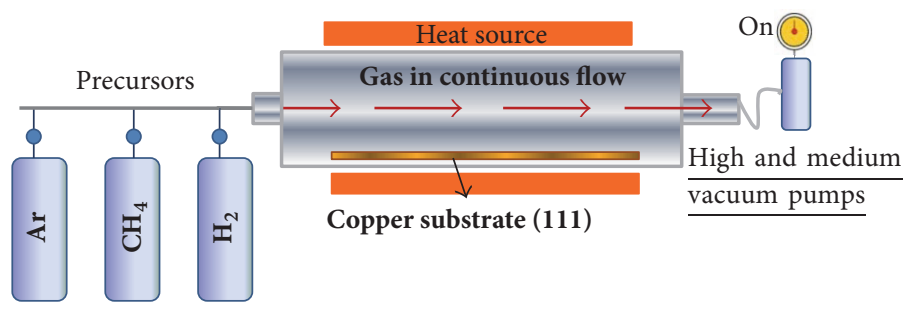

(b)

FIGURE 1: Schematic representation of the graphene synthesis with (a) proposed method at atmosphere pressure using polycrystalline substrate and gas discontinuous flow and (b) traditional process at high vacuum using monocrystalline substrate and gas continuous flow.

of $\mathrm{N}_{2}$ gas was introduced into the reactor for $15 \mathrm{~min}$ to remove the present oxygen. Then $1 \mathrm{~L} / \mathrm{min}$ of $\mathrm{N}_{2} / \mathrm{H}_{2}$ was introduced to reduce the copper oxides in the surface of the sheet. Afterwards, on the one hand, acetylene was injected to the reactor at constant flow rate for $1 \mathrm{~min}$. The injection was stopped in order to start the graphene growth process with the gas trapped inside reactor at different temperatures (Table 2). The cooling down was carried out under nitrogen atmosphere with a ramp of $8^{\circ} \mathrm{C} / \mathrm{min}$.

2.3. Characterization. Graphene layers were analyzed in a high-resolution transmission electron microscope (HRTEM) JEOL-JEM 2200FS equipped with a spherical aberration corrector in the condenser lens and operated at $200 \mathrm{kV}$. Images were acquired in STEM mode, with bright field (BF) and high angle annular dark field (HAADF) detectors. Also, atomic force microscopy (AFM) was used, Asylum, model MFP3D-SA, using the technique of noncontact mode or AC, with rectangular cantilever model AC240TS-R3 at $2 \mathrm{~N} / \mathrm{m}$ and a scanning speed of $70 \mathrm{kHz}$. The Raman spectra of graphene layers on copper substrate were recorded using a Renishaw in Via Raman spectrometer with an electronically cooled $\left(-70^{\circ} \mathrm{C}\right) \mathrm{CCD}$ camera and a Leica microscope. The excitation source used was a He-Ne laser with emission at $633 \mathrm{~nm}$; integration time was 10 seconds. A diffraction grating at 1200 lines $/ \mathrm{mm}$ and objective of 50x magnification with numerical aperture of 0.75 were used.

\section{Results and Discussion}

3.1. Graphene Synthesis by CVD. Table 1 shows an overview of CVD processes used with different gas precursors and growth conditions. Unlike the conditions mentioned in Table 1, our process allows the graphene synthesis, in a maximum time of $66 \mathrm{~min}$, without making use of vacuum pumps. Note that for similar times of synthesis, pressures of $3-9 \times 10^{-2}$ torr are
TABLE 2: Evaluated temperatures for the growth process.

\begin{tabular}{lcccc}
\hline Heating & Cleaning & \multicolumn{2}{c}{ Growth } & Cooling \\
$T\left({ }^{\circ} \mathrm{C}\right)$ & Time & $\begin{array}{c}\text { Flow rate } \\
\mathrm{C}_{2} \mathrm{H}_{2}(\mathrm{sccm})\end{array}$ & $\begin{array}{c}\text { Reaction } \\
\text { time }\end{array}$ & Time \\
\hline $1000^{\circ} \mathrm{C}$ & $30 \mathrm{~min}$ & 100 & $5 \mathrm{~min}$ & 30 \\
$900^{\circ} \mathrm{C}$ & $30 \mathrm{~min}$ & 100 & $5 \mathrm{~min}$ & 30 \\
$800^{\circ} \mathrm{C}$ & $30 \mathrm{~min}$ & 100 & $5 \mathrm{~min}$ & 30 \\
\hline
\end{tabular}

required in most of the processes reported in Table 1 while atmospheric pressure is used in ours. Also in our process $\mathrm{N}_{2}$ is used as carrier gas instead of using argon, which is more expensive.

The proposed synthesis method is compound by four stages (cleaning, precursor injection, reaction time, and cooling). The temperature and flowrate of carbon precursor were the studied parameters. In Figure 1(a) the traditional process and differences with our process are shown.

In the first stage, the process temperatures 800,900 , and $1000^{\circ} \mathrm{C}$ were evaluated as shown in Table 2 . The objective was to know the temperature at which amorphous carbon is formed and avoid it in the following tests. A flowrate at $100 \mathrm{sccm}$ of acetylene was used as reference.

In the second stage, acetylene gas flowrate was tested at $100,80,30$, and $10 \mathrm{sccm}$ as shown in Table 3. The heating temperature was fixed after obtaining the results being $1000^{\circ} \mathrm{C}$, the temperature which avoids the amorphous carbon deposition.

3.2. Proposed Reaction Mechanism. For graphene synthesis by CVD the use of both saturated and unsaturated hydrocarbons is essential $[5,8,37,38]$. Saturated hydrocarbons are stable and less reactive than unsaturated hydrocarbons. $\mathrm{C}_{2} \mathrm{H}_{2}$ has a positive Gibbs free energy formation with a value of $\Delta \mathrm{G}=209 \mathrm{KJ} / \mathrm{mol}$, indicating that reactants are favored in the 
TABLE 3: Evaluated acetylene gas flow rates.

\begin{tabular}{|c|c|c|c|c|}
\hline Heating & Cleaning & Growth & & Cooling \\
\hline$T\left({ }^{\circ} \mathrm{C}\right)$ & Time (min) & $\begin{array}{c}\text { Injection } \mathrm{C}_{2} \mathrm{H}_{2} \times 1 \mathrm{~min} \\
(\mathrm{sccm})\end{array}$ & $\begin{array}{l}\text { Reaction time } \\
(\min )\end{array}$ & $\begin{array}{l}\text { Time } \\
(\mathrm{min})\end{array}$ \\
\hline 1000 & 30 & 100 & 5 & 30 \\
\hline 1000 & 30 & 80 & 5 & 30 \\
\hline 1000 & 30 & 30 & 5 & 30 \\
\hline 1000 & 30 & 10 & 5 & 30 \\
\hline
\end{tabular}

following reaction: $2 \mathrm{C}_{(\mathrm{s})}+\mathrm{H}_{2(\mathrm{~g})}=\mathrm{C}_{2} \mathrm{H}_{2(\mathrm{~g})}$ [39, 40]. According to thermodynamics data, $\mathrm{C}_{2} \mathrm{H}_{2}$ begins to decompose at $25^{\circ} \mathrm{C}$ and is highly reactive. Figure 2 shows a comparison of $\Delta \mathrm{G}_{\mathrm{f}}^{\circ}$ between $\mathrm{C}_{2} \mathrm{H}_{2}$ and other hydrocarbons that have commonly been used in graphene synthesis [41]. As can be seen in Figure 2, as temperature increases, methane retains more stability when compared with acetylene $\left(\mathrm{CH}_{4}>\mathrm{C}_{2} \mathrm{H}_{6}>\right.$ $\mathrm{C}_{2} \mathrm{H}_{4}>\mathrm{C}_{2} \mathrm{H}_{2}$ ). Thus, acetylene presents a positive $\Delta \mathrm{G}_{\mathrm{f}}^{\circ}$ in a wide range of temperatures unlike methane which has a negative $\Delta \mathrm{G}_{\mathrm{f}}^{\circ}$ in temperatures lower than $500^{\circ} \mathrm{C}$.

Since acetylene is highly reactive, it might interact within the reactor with hydrogen, generating hydrogenation reactions. Thus other hydrocarbon species can be formed. To gain insight into the possible reactions occurring within the CVD furnace, the following acetylene reactions were analyzed:

$$
\begin{aligned}
\mathrm{C}_{2} \mathrm{H}_{2(\mathrm{~g})} & =2 \mathrm{C}+\mathrm{H}_{2(\mathrm{~g})} \\
\mathrm{C}_{2} \mathrm{H}_{2(\mathrm{~g})}+\mathrm{H}_{2(\mathrm{~g})} & =\mathrm{C}_{2} \mathrm{H}_{4(\mathrm{~g})} \\
\mathrm{C}_{2} \mathrm{H}_{2(\mathrm{~g})}+2 \mathrm{H}_{2(\mathrm{~g})} & =\mathrm{C}_{2} \mathrm{H}_{6(\mathrm{~g})} \\
\mathrm{C}_{2} \mathrm{H}_{2(\mathrm{~g})}+3 \mathrm{H}_{2(\mathrm{~g})} & =2 \mathrm{CH}_{4(\mathrm{~g})} \\
\mathrm{CH}_{4(\mathrm{~g})} & =\mathrm{C}+2 \mathrm{H}_{2(\mathrm{~g})}
\end{aligned}
$$

The variation of the standard Gibbs free energy change with temperature is

$$
\Delta \mathrm{G}=\Delta H_{T}^{0}-T \Delta S_{T}^{0}
$$

where

$$
\begin{aligned}
\Delta \mathrm{G}_{T}^{0}= & \Delta H_{298}^{0}+\int_{298}^{T} \Delta C p d T-T \Delta S_{298}^{0} \\
& -T \int_{298}^{T} \frac{\Delta C p}{T} d T
\end{aligned}
$$

[42] and

$$
\Delta \mathrm{G}_{T}^{0}=-R T \ln K,
$$

where $K$ is the equilibrium constant.

The constant $K$ allows knowing the behavior of a reaction by increasing the temperature; therefore, for $\log K>1$, the reaction favors the products, while for $\log K<1$ the reaction favors the reagents [39]. Figure 3 shows the $\log K$ for acetylene hydrogenation reactions as well as its dehydrogenation reaction.

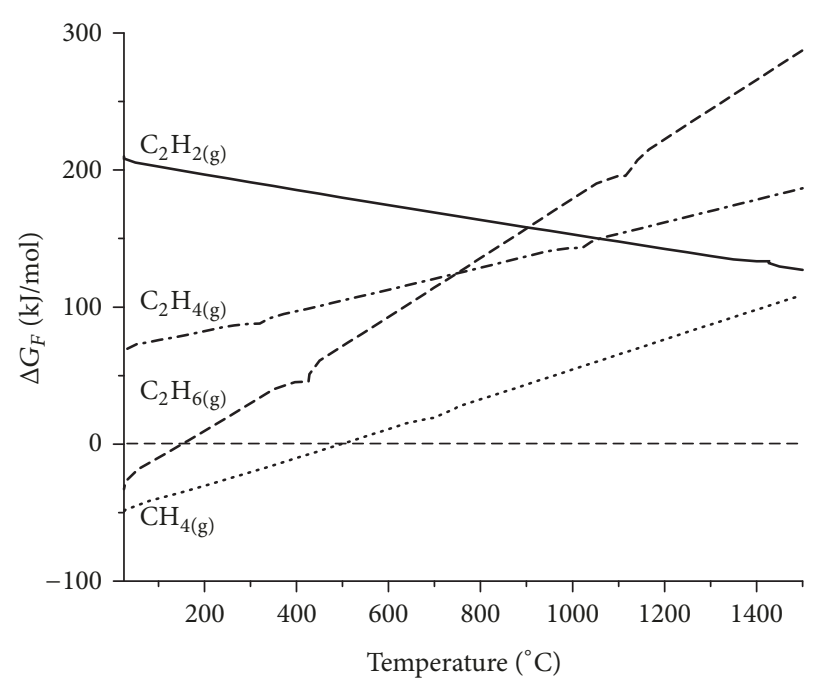

FIGURE 2: Stability of hydrocarbon species.

It is important to take into account that, within the experimental temperature range, for all reactions, the value of $\log K$ is greater than 1 , for all reactions, and that the most favored reaction is the dehydrogenation of acetylene (solid line curve, Figure 3). Thus, acetylene is more susceptible to dehydrogenation rather than hydrogenation and releases carbon atoms for nucleation and graphene growth.

3.3. Transmission Electron Microscopy. Figure 4 shows typical micrographs obtained by electron transmission microscopy using dark and bright field illumination mode. By means of this technique, some highlights of the sample are visible which are difficult to observe in normal mode. Basically, transparent parts of the sample are shown in dark while the particles appear bright since they receive and scatter light in different directions. The results show sheets that were pulled up from $\mathrm{Cu}$ substrates during sonication. In Figure 4, images that appear at the top show the bright field and the corresponding dark field STEM images appear at the bottom. The acetylene flow was fixed at $100 \mathrm{sccm}$ and images in the left, center and right side correspond to temperatures of 1000, 900, and $800^{\circ} \mathrm{C}$, respectively (Table 2 ). Both images at $1000^{\circ} \mathrm{C}$ show the presence of few layers of graphene in contrast to the other temperatures $\left(900\right.$ and $\left.800^{\circ} \mathrm{C}\right)$. In samples obtained at $900^{\circ} \mathrm{C}$ the presence of graphene layers and carbon agglomerates as brighter areas (bottom) was observed. This effect can be attributed to the stacking of carbon atoms on the nucleation 


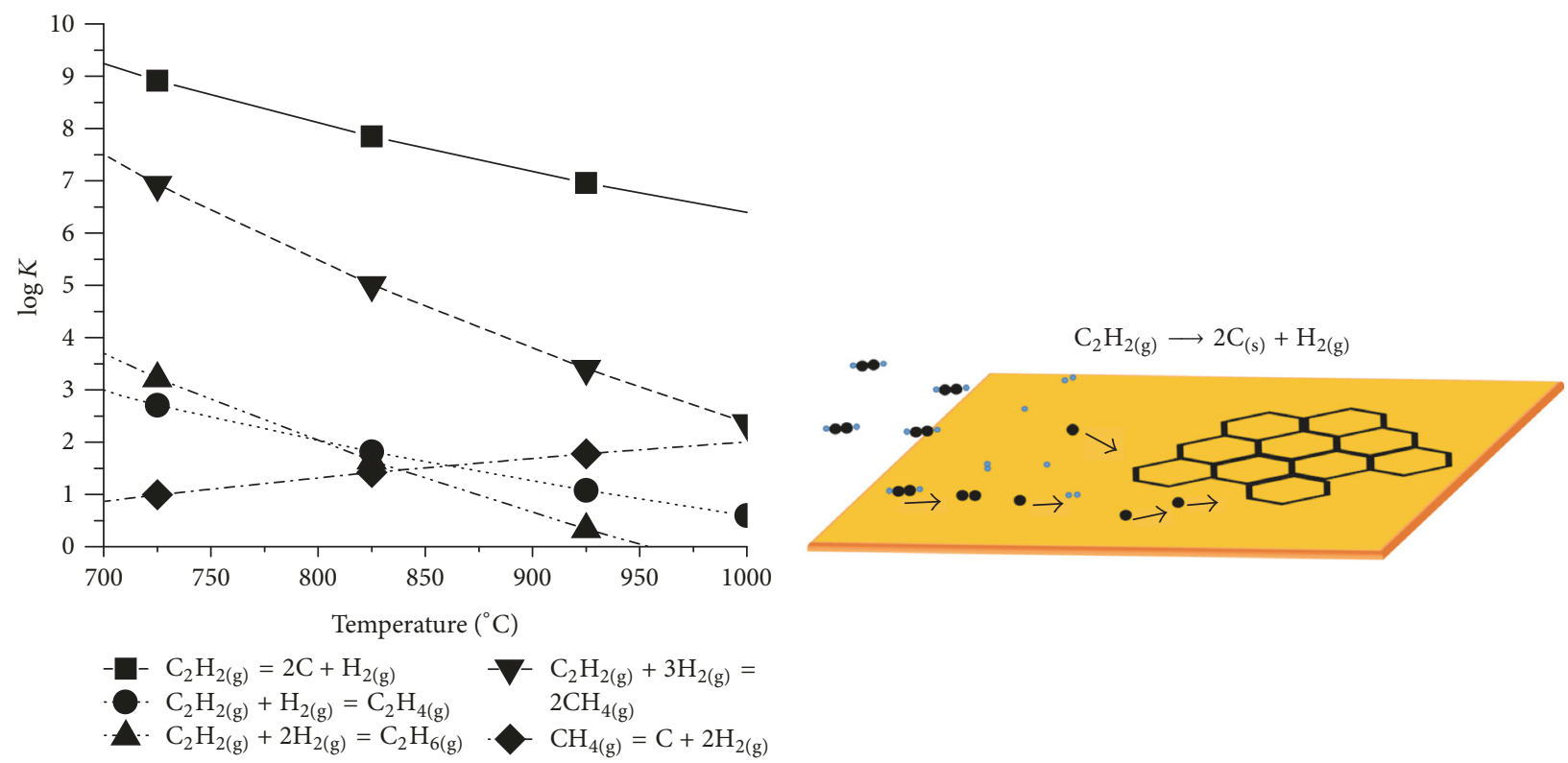

(a)

(b)

FIgURE 3: (a) $\log K$ for acetylene hydrogenation reactions and acetylene dehydrogenation. (b) Acetylene disintegration mechanism.

centers, which avoid the epitaxial growth of graphene sheets. Similarly, in process at $800^{\circ} \mathrm{C}$, carbonaceous agglomerates are observed on a graphene sheet (top) confirming the agglomeration hypothesis using low temperatures. Initially, acetylene is decomposed on the copper surface facilitating the growth of a graphene sheet; nonetheless, under the growth conditions studied in this work, carbon precipitations were observed for process with temperatures below $900^{\circ} \mathrm{C}$.

Additionally, the effect of acetylene flowrate was studied (see Table 3) maintaining a fixed temperature at $1000^{\circ} \mathrm{C}$ as a direct consequence of the obtained results. The objective was reducing the amount the amount of graphene layers previously obtained with a flow of $100 \mathrm{sccm}$.

The presence of fairly thin sheets of graphene was achieved with a flow rate of $80 \mathrm{sccm}$ (Figures 5(a) and 5(b)). In Figures 5(c), 5(d), and 5(e), samples where graphene was synthesized using $30 \mathrm{sccm}$ can be seen. However, when acetylene flow rate of $10 \mathrm{sccm}$ (data not shown) was tested, no graphene layers were observed, concluding that the flow rate of $10 \mathrm{sccm}$ is not enough as carbon precursor.

3.4. Raman Spectroscopy. Raman spectroscopy was carried out in order to evaluate the structure of the graphene film growth at different conditions. This spectroscopy technique has been used to probe structural and physical properties of graphitic materials, providing valuable information about the atomic structure of edges, presence of disorder, defects, charges, and strain [43].

Figure 6 shows the characteristic spectra of this kind of carbonaceous materials. The analysis of Raman is focused on the $\mathrm{D}, \mathrm{G}$, and 2D bands of the spectrum, which are expected to appear at $\sim 1350 \mathrm{~cm}^{-1}, \sim 1580 \mathrm{~cm}^{-1}$, and $\sim 2680 \mathrm{~cm}^{-1}$, respectively [44]. D band corresponds to disordered structure in graphene, especially at the edges of the graphene sheets. The $\mathrm{G}$ peak originates from the first-order scattering process due to the double degenerate phonon mode vibrations at the center of Brillouin zone and is related to $\mathrm{sp}^{2}$ bonded carbon [45]. Measurement of $I_{\mathrm{D}} / I_{\mathrm{G}}$ ratio is a well-known method for characterization of disorder [46, 47]. Ferrari et al. [48] showed that it is possible to use the second-order 2D (or $\mathrm{G}^{\prime}$ ) band in the graphene Raman spectra to learn about the number of layers in a graphene sample by using the $I_{2 \mathrm{D}} / I_{\mathrm{G}}$ ratio [49].

On one hand, as can be seen in Figure 6(a) (black line), sample obtained at $800^{\circ} \mathrm{C}$ shows a spectrum with a lot of defects in the structure of the material. Peaks D and $G$ are overlapped by a combination of $\mathrm{sp} 2$ and $\mathrm{sp} 3$ bonds, corresponding to the presence of structural disorder or defects [47]. Thus, these spectroscopic results and those obtained by using the microscopic technique indicate that $800^{\circ} \mathrm{C}$ is not an adequate temperature for the synthesis of graphene since different carbon species are obtained.

Samples obtained at 1000 and $900^{\circ} \mathrm{C}$ (Figure 6(a), blue and red lines, respectively) present spectra with the three principal graphene peaks, which are consistent with the results observed in micrographs from Figure 4. Therefore, both temperatures could be adequate for the synthesis of carbon laminar structures. Nonetheless, for some cases, the $I_{\mathrm{D}} / I_{\mathrm{G}}$ intensity ratio is high according to Malard et al., indicating that a greater intensity in the $\mathrm{D}$ band is attributed to defects such as incomplete carbon-carbon bonds at edges. On the other hand, as shown in Figure 6(c), a $I_{2 \mathrm{D}} / I_{\mathrm{G}}$ ratio value lower than two was obtained, which indicates that the synthesized graphene consists of multilayers [31]. At 


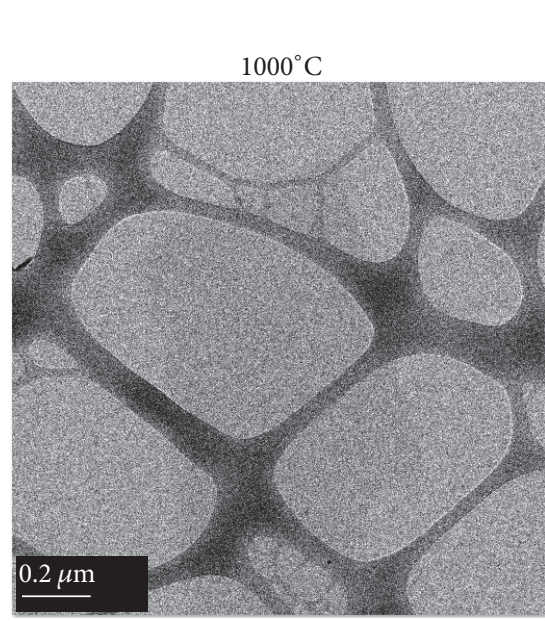

(a)

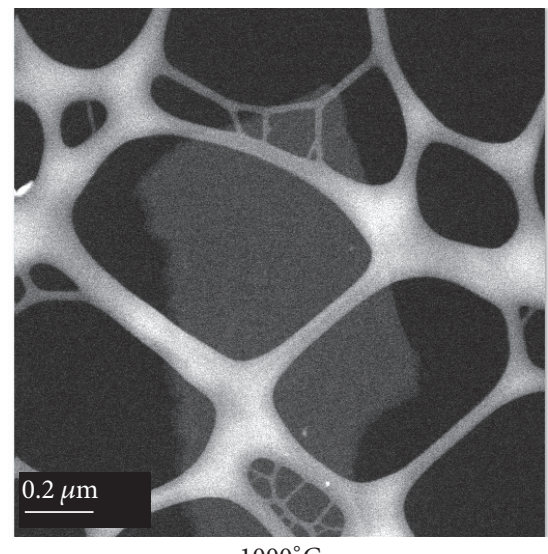

$1000^{\circ} \mathrm{C}$

(b)

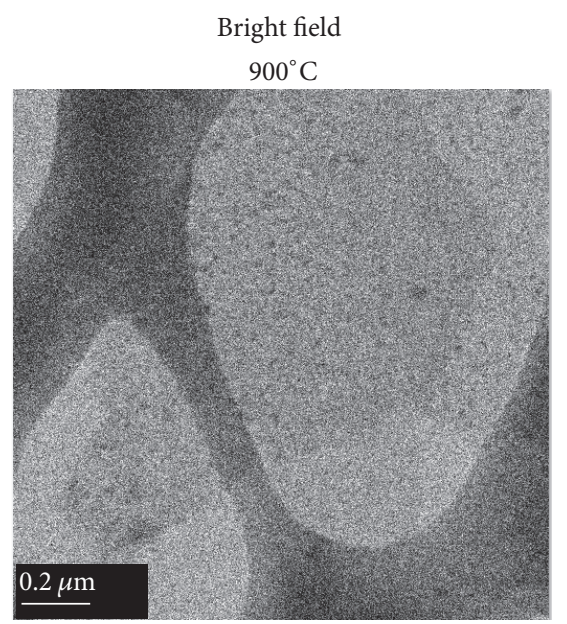

(c)

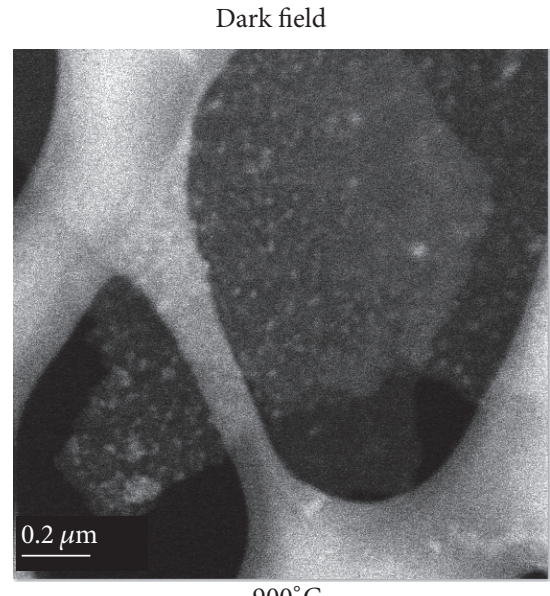

(d)

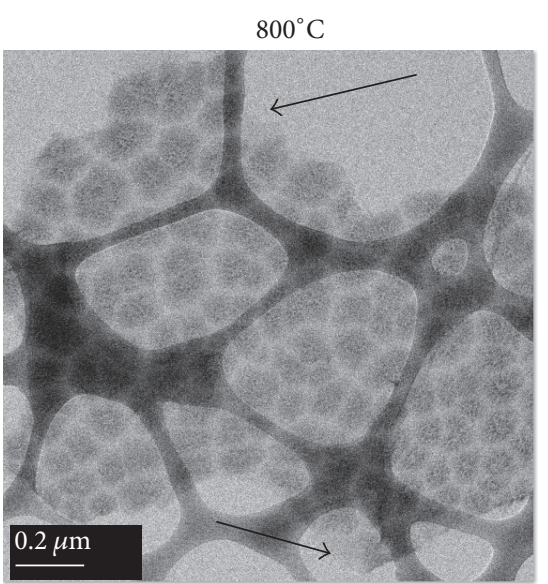

(e)

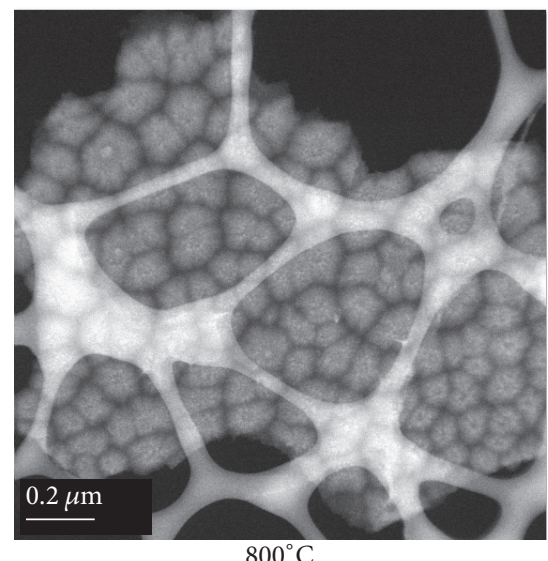

(f)

Figure 4: TEM bright (top) and dark field images (bottom) of graphene. Acetylene flow was fixed at $100 \mathrm{sccm}$. Samples obtained at different temperatures $\left(1000,900\right.$, and $\left.800^{\circ} \mathrm{C}\right)$.

$1000^{\circ} \mathrm{C}$ an increase in this ratio $\left(I_{2 \mathrm{D}} / I_{\mathrm{G}}\right)$ with respect to 800 and $900^{\circ} \mathrm{C}$ was observed. Thus, $1000^{\circ} \mathrm{C}$ was chosen as the synthesis temperature for further experiments.

As previously discussed, in order to reduce the number of layers and defects, different acetylene flowrates were tested in the synthesis of graphene. For this case, experiments were carried out by using 100, 80, 30, and $10 \mathrm{sccm}$ of acetylene per minute of synthesis. The Raman spectra indicate that an acetylene flowrate of $30 \mathrm{sccm}$ produces a $2 \mathrm{D}$ band two times more intense than the G band (Figure 6(b), blue line). An increase in the intensity of the $2 \mathrm{D}$ peak as well as a decrease of the $\mathrm{D}$ band may indicate a lower number of layers and fewer defects (Figure 6(d)).

The $I_{2 \mathrm{D}} / I_{\mathrm{G}}$ ratio obtained by using a gas flowrate of $80 \mathrm{sccm}$ was of 1.3 , while the ratio $I_{2 \mathrm{D}} / I_{\mathrm{G}}$ with a flowrate of $30 \mathrm{sccm}$ was 2.5. In both cases, a reduction in the number of defects was observed (Figure 6(d)); however, its presence is expected due to polycrystallinity in the $\mathrm{Cu}$ substrate. It is important to take into account the fact that the $\mathrm{Cu}$ grain boundaries and the edges of the graphene domains promote defects in its structure [43]. However the honeycomb shaped arrangement predominates in the entire structure. A ratio of $I_{2 \mathrm{D}} / I_{\mathrm{G}}>2$ indicates the presence of graphene near to monolayer [21, 50-52] which indicates the production of a film with high quality (Figure 6(d)) [53].

3.5. Atomic Force Spectroscopy. AFM is one of the most important characterization techniques used to elucidate the amount of graphene layers present in a material. Figure 7 shows micrographs of graphene synthesized at $1000^{\circ} \mathrm{C}$ and with different acetylene flowrates. Synthesis carried out with $100 \mathrm{sccm}$ (Figure 7(a)) renders plates with a thickness of $5.08 \mathrm{~nm}$. Under these conditions, the 2D peak in Raman was small, but TEM micrographs showed hardly any laminar structures (data not shown). Assuming a distance between layers of approximately $0.34 \mathrm{~nm}$ [54], the number of layers could be set at 14 . While, at flow rate of $80 \mathrm{sccm}$, plate thickness was $3.29 \mathrm{~nm}$, corresponding to 8 graphene layers. Finally, injecting acetylene at $30 \mathrm{sccm}$ generated plates of $1.65 \mathrm{~nm}$, corresponding to approximately 4 layers of graphene. 


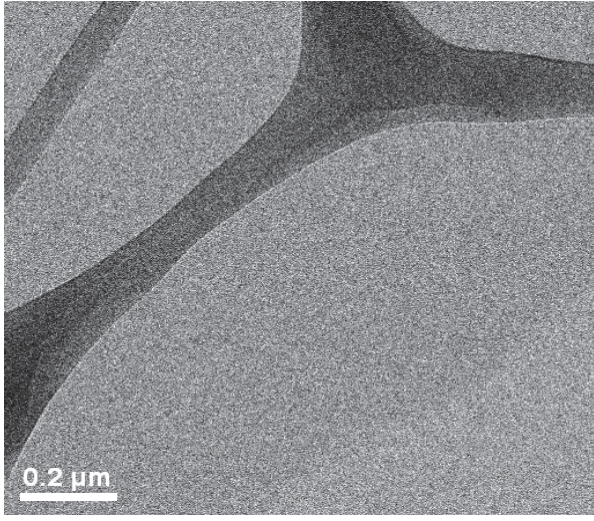

(a)

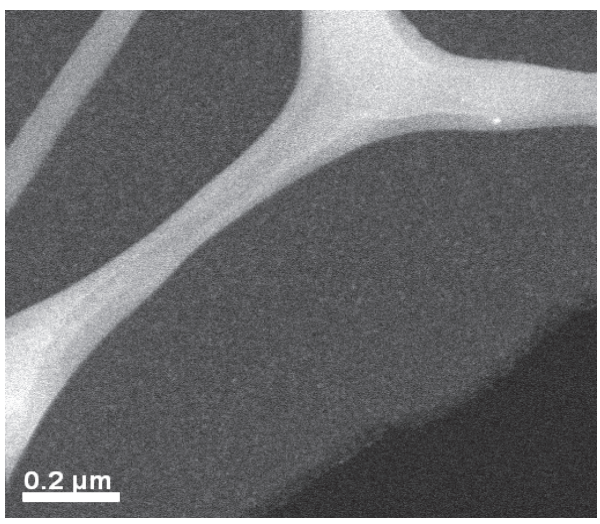

(c)

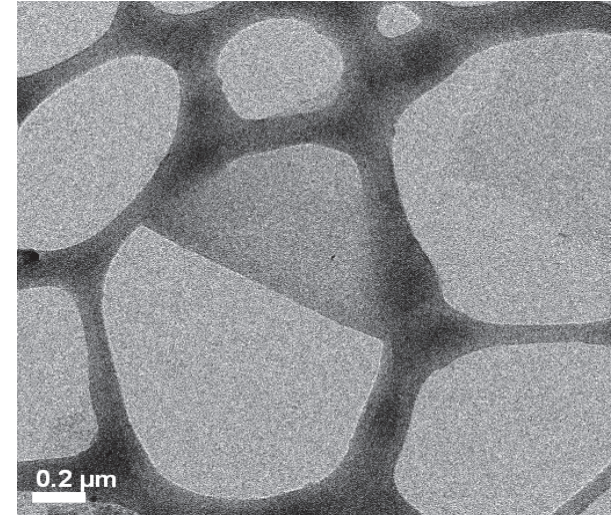

(b)

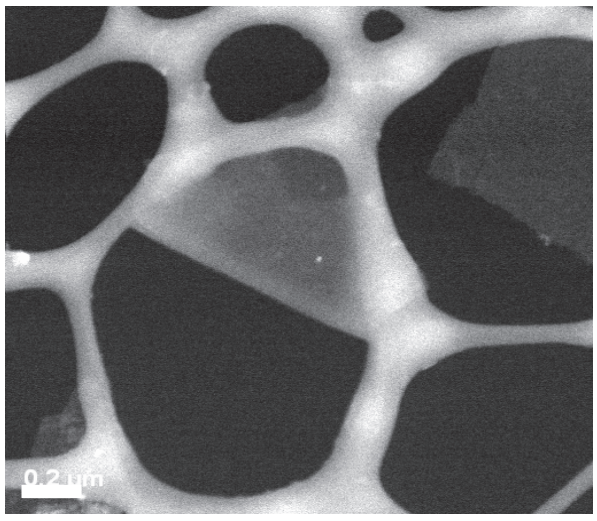

(d)

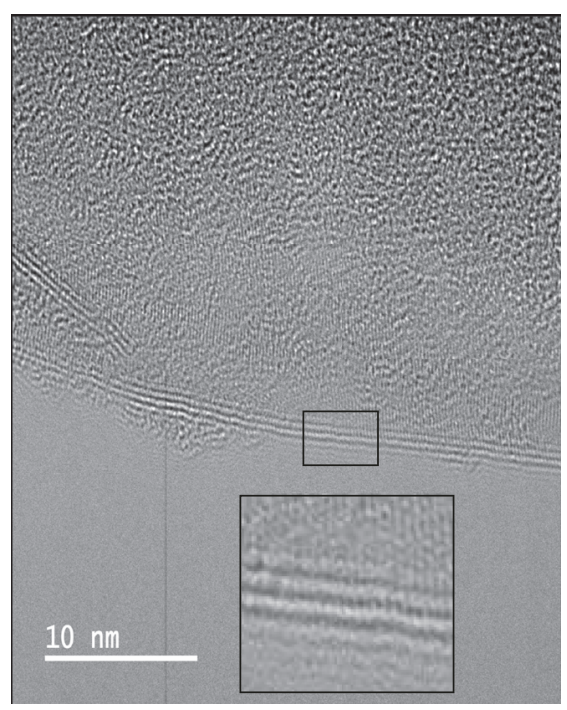

(e)

FIGURE 5: TEM bright and dark field images for graphene growth with fixed temperature at $1000^{\circ} \mathrm{C}$ and acetylene flowrates of 80 (a, b) and $30 \mathrm{sccm}(\mathrm{c}, \mathrm{d}$, and e).

\section{Conclusions}

The method described in this work offers important advantages such as (1) the number of parameters was simplified; (2) time of synthesis is shorter than those used in traditional methods; (3) it is a low-cost method when compared to those that using a continuous gas flowrates; (4) the proposed process in batch, besides using lower gas consumption, represents a significant reduction of emissions in the environment; (5) besides, the use of electrolytic technical grade copper instead of monocrystalline copper (reagent grade or high 


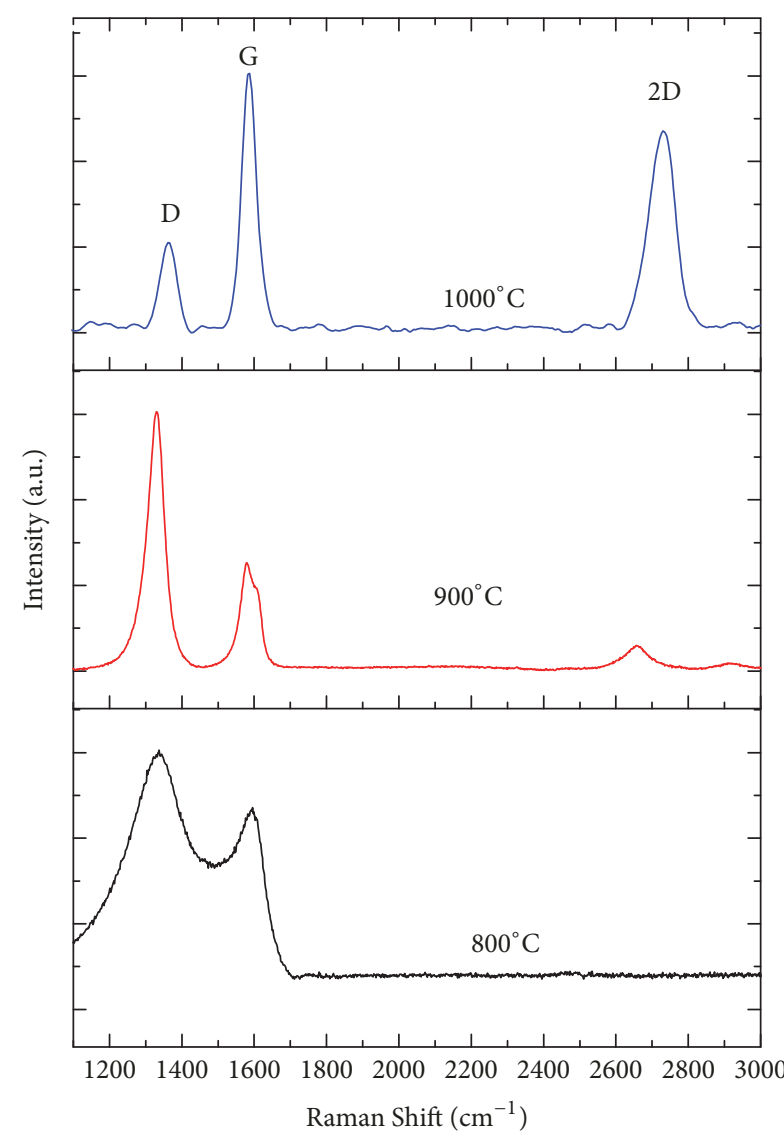

(a)

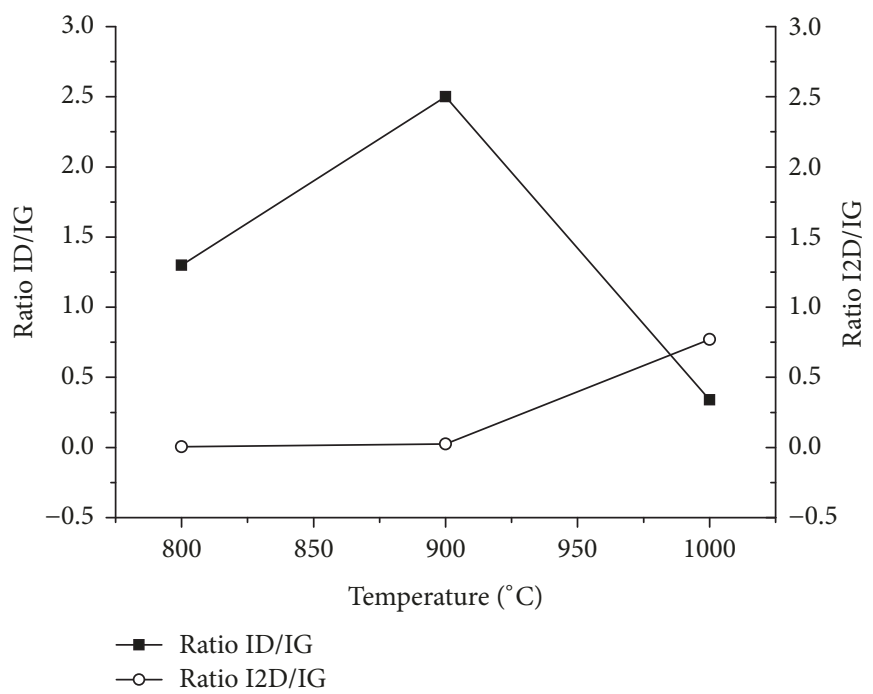

(c)

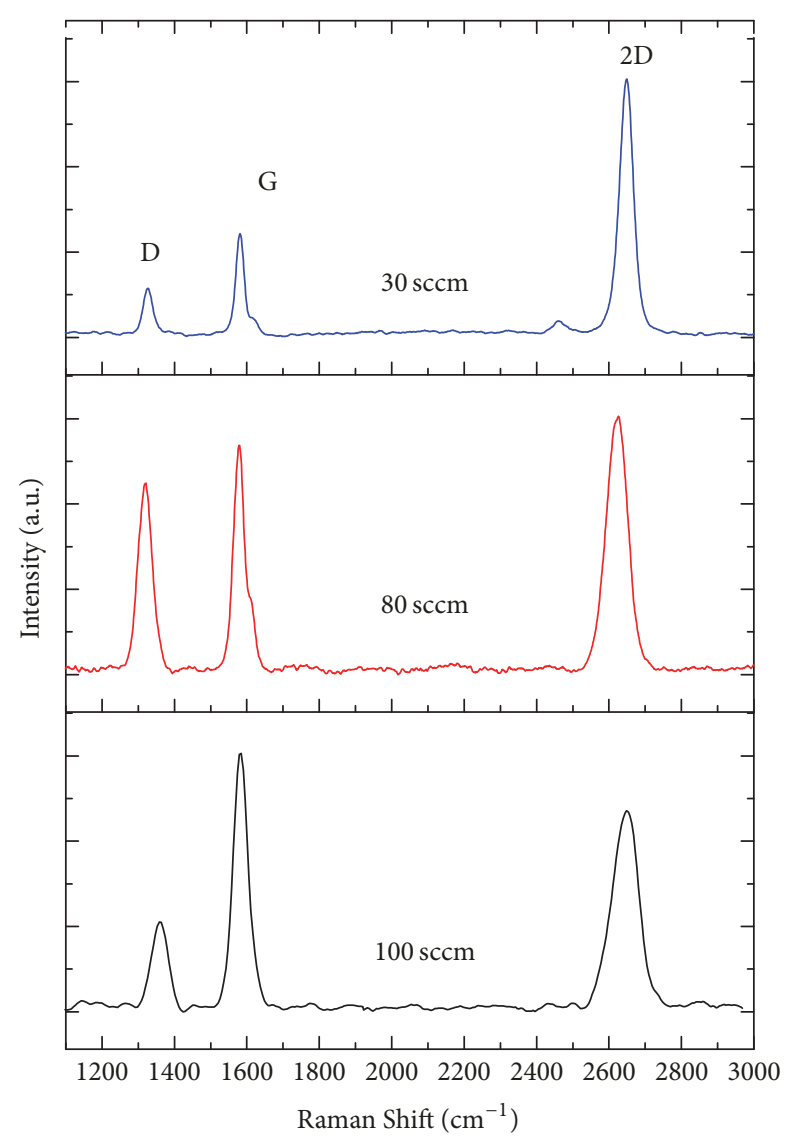

(b)

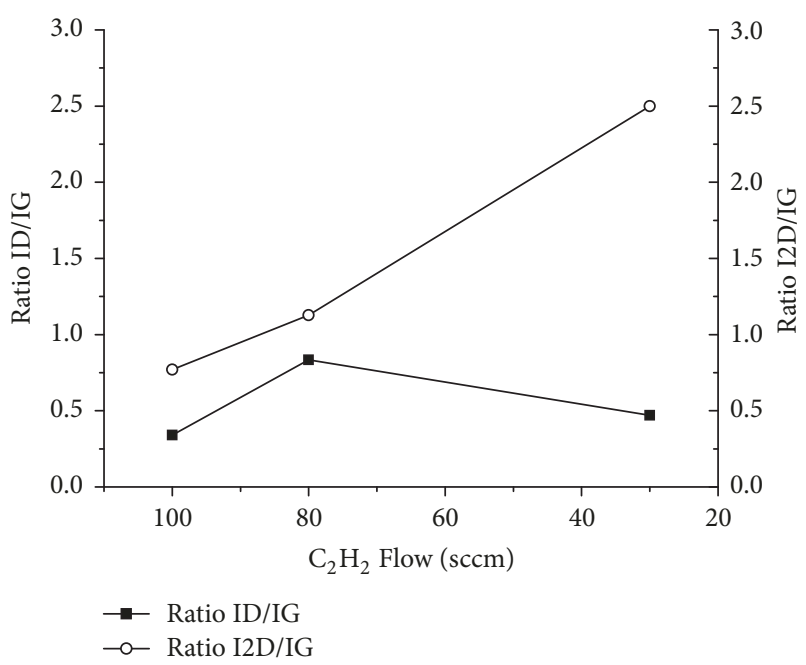

(d)

FIGURE 6: Raman spectra for (a) graphene synthesized at different temperatures with a fixed $\mathrm{C}_{2} \mathrm{H}_{2}$ flowrate (100 sccm) and (b) with different $\mathrm{C}_{2} \mathrm{H}_{2}$ flow rates at $1000^{\circ} \mathrm{C}$. Schematic representation for $I_{\mathrm{D}} / I_{\mathrm{G}}$ and $I_{2 \mathrm{D}} / I_{\mathrm{G}}$ ratios at (c) fixed flow rate and (d) fixed temperature.

purity cooper foil) also contributes to reducing costs; (6) finally, the use of a mixture of $\mathrm{N}_{2} / \mathrm{H}_{2}(90: 10)$ instead of pure $\mathrm{H}_{2}$, decreases the explosive risk by gas accumulation. In general, the synthesized graphene shows a good quality with spectral characteristics very near to the monolayer graphene; therefore, the obtained material with the proposed method represents an attractive option for industrial purposes or graphene mass production. 

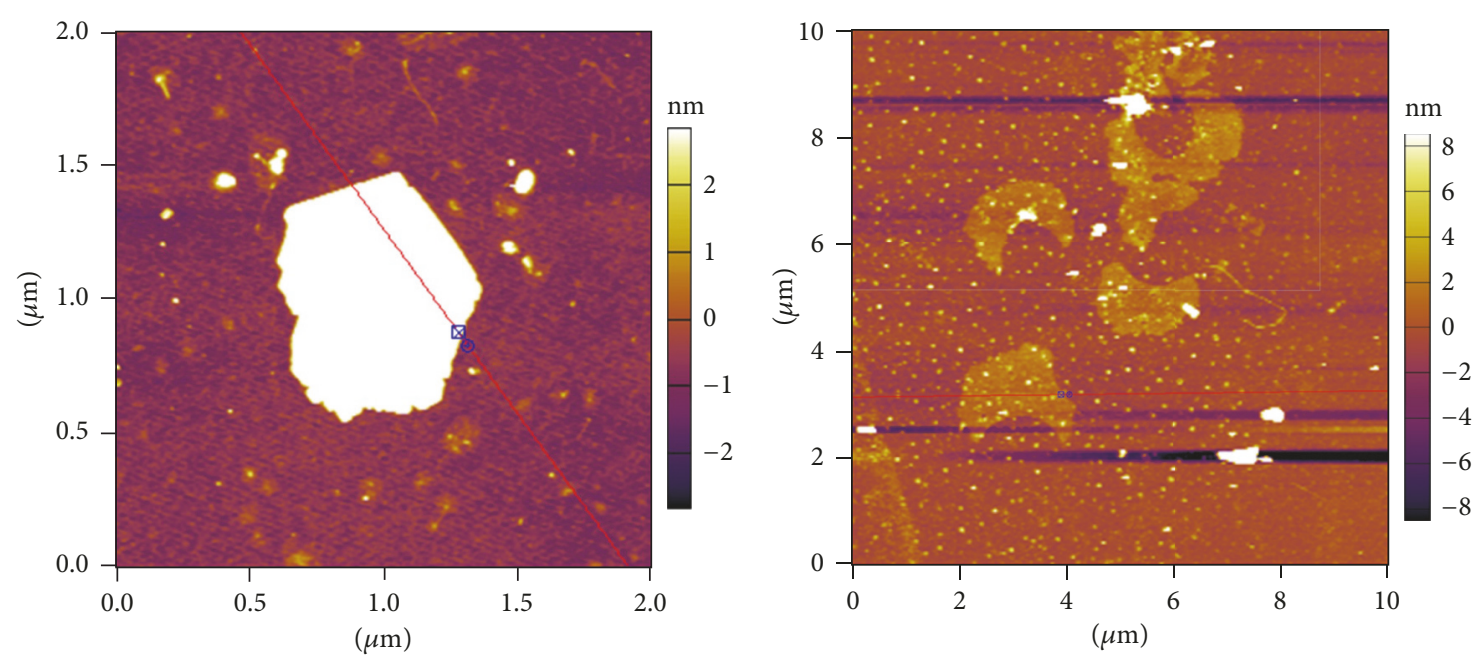

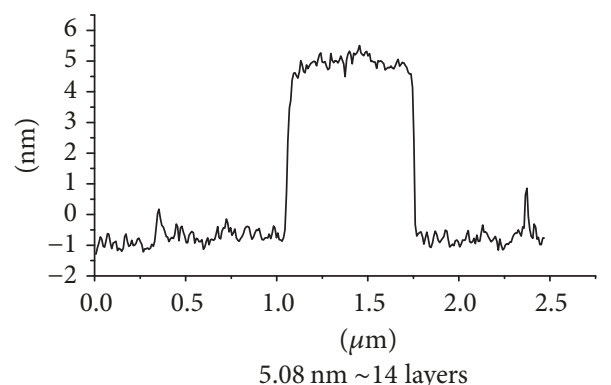

(a)

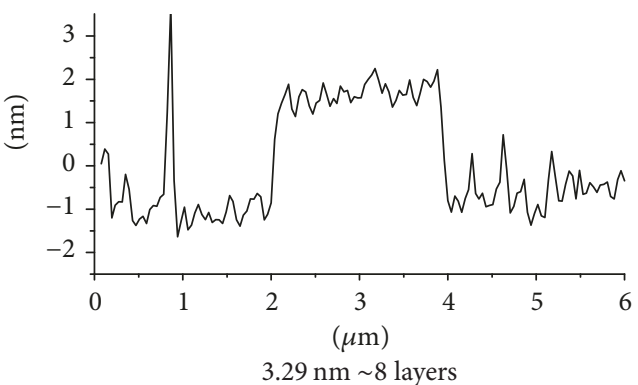

(b)
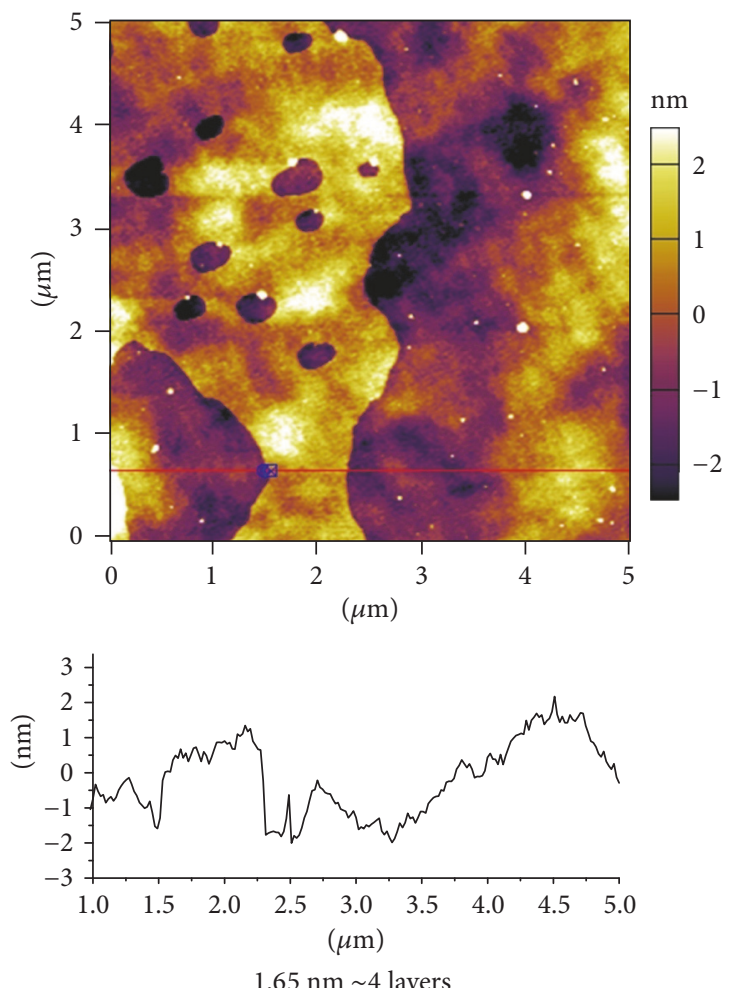

(c)

FIGURE 7: AFM micrographs of graphene obtained at $1000^{\circ} \mathrm{C}$ and with different acetylene flow rates: (a) $100 \mathrm{sccm}$, (b) $80 \mathrm{sccm}$, and (c) $30 \mathrm{sccm}$. 


\section{Conflicts of Interest}

The authors declare that there are no conflicts of interest regarding the publication of this paper.

\section{Acknowledgments}

The financial support by CONACyT is acknowledged. The authors thank Oscar Eduardo Vega Becerra from CIMAV, Luz Maria Avilez from CINVESTAV QRO, and Iris Aguilar Hernández from ITESM Campus Monterrey for the technical support.

\section{References}

[1] B. Wu, D. Geng, Y. Guo et al., "Equiangular hexagon-shapecontrolled synthesis of graphene on copper surface," Advanced Materials, vol. 23, no. 31, pp. 3522-3525, 2011.

[2] M. H. Rümmeli, S. Gorantla, A. Bachmatiuk et al., "On the role of vapor trapping for chemical vapor deposition (CVD) grown graphene over copper," Chemistry of Materials, vol. 25, no. 24, pp. 4861-4866, 2013.

[3] J. W. Suk, A. Kitt, C. W. Magnuson et al., "Transfer of CVDgrown monolayer graphene onto arbitrary substrates," ACS Nano, vol. 5, no. 9, pp. 6916-6924, 2011.

[4] L. S. Bernard, M. Spina, J. Jacimovic et al., "Functionalized graphene grown by oxidative dehydrogenation chemistry," Carbon, vol. 71, pp. 11-19, 2014.

[5] G. Nandamuri, S. Roumimov, and R. Solanki, "Chemical vapor deposition of graphene films," Nanotechnology, vol. 21, no. 14, Article ID 145604, 2010.

[6] Z.-S. Wu, G. Zhou, L.-C. Yin, W. Ren, F. Li, and H.-M. Cheng, "Graphene/metal oxide composite electrode materials for energy storage," Nano Energy, vol. 1, no. 1, pp. 107-131, 2012.

[7] B. Wang, Y. Zhang, H. Zhang et al., "Wrinkle-dependent hydrogen etching of chemical vapor deposition-grown graphene domains," Carbon, vol. 70, pp. 75-80, 2014.

[8] J. Kim, J. Seo, H. Kyung, S. H. Kim, and H. Woo, "The effect of various parameters for few-layered graphene synthesis using meth- ane and acetylene," Journal of Ceramic Processing Research, vol. 13, no. 1, pp. 42-46, 2012.

[9] S. Bhaviripudi, X. Jia, M. S. Dresselhaus, and J. Kong, "Role of kinetic factors in chemical vapor deposition synthesis of uniform large area graphene using copper catalyst," Nano Letters, vol. 10, no. 10, pp. 4128-4133, 2010.

[10] H. Kim, C. Mattevi, M. R. Calvo et al., "Activation energy paths for graphene nucleation and growth on Cu," ACS Nano, vol. 6, no. 4, pp. 3614-3623, 2012.

[11] H. H. Kim, Y. Chung, E. Lee, S. K. Lee, and K. Cho, "Water-free transfer method for CVD-grown graphene and its application to flexible air-stable graphene transistors," Advanced Materials, vol. 26, no. 20, pp. 3213-3217, 2014.

[12] C.-M. Seah, S.-P. Chai, and A. R. Mohamed, "Mechanisms of graphene growth by chemical vapour deposition on transition metals," Carbon, vol. 70, pp. 1-21, 2014.

[13] J. Cho, L. Gao, J. Tian et al., "Atomic-scale investigation of graphene grown on $\mathrm{Cu}$ foil and the effects of thermal annealing," ACS Nano, vol. 5, no. 5, pp. 3607-3613, 2011.

[14] M. Batzill, “The surface science of graphene: Metal interfaces, CVD synthesis, nanoribbons, chemical modifications, and defects," Surface Science Reports, vol. 67, no. 3-4, pp. 83-115, 2012.

[15] C. Wang, B. Xiao, and Y.-H. Ding, “Theoretical investigation on the healing mechanism of divacancy defect in graphene growth by reaction with ethylene and acetylene," New Journal of Chemistry, vol. 37, no. 3, pp. 640-645, 2013.

[16] A. Guermoune, T. Chari, F. Popescu et al., "Chemical vapor deposition synthesis of graphene on copper with methanol, ethanol, and propanol precursors," Carbon, vol. 49, no. 13, pp. 4204-4210, 2011.

[17] S. M. Kim, A. Hsu, and Y. Lee, "Graphene growth with "no" feedstock," 2D Materials, vol. 4, article 25089, 2017.

[18] I. Vlassiouk, M. Regmi, P. Fulvio et al., "Role of hydrogen in chemical vapor deposition growth of large single-crystal graphene," ACS Nano, vol. 5, no. 7, pp. 6069-6076, 2011.

[19] W. Zhang, P. Wu, Z. Li, and J. Yang, "First-principles thermodynamics of graphene growth on Cu surfaces," The Journal of Physical Chemistry C, vol. 115, no. 36, pp. 17782-17787, 2011.

[20] S. Dhingra, J.-F. Hsu, I. Vlassiouk, and B. D’Urso, “Chemical vapor deposition of graphene on large-domain ultra-flat copper," Carbon, vol. 69, pp. 188-193, 2014.

[21] M. Ishihara, Y. Koga, J. Kim, K. Tsugawa, and M. Hasegawa, "Direct evidence of advantage of $\mathrm{Cu}(111)$ for graphene synthesis by using Raman mapping and electron backscatter diffraction," Materials Letters, vol. 65, no. 19-20, pp. 2864-2867, 2011.

[22] Y.-P. Hsieh, M. Hofmann, and J. Kong, "Promoter-assisted chemical vapor deposition of grapheme," Carbon, vol. 67, pp. 417-423, 2014.

[23] Z. Liu, L. Li, H. Ren, and X. Sun, “Thermal Transport in CarbonBased Nanomaterials," Copyright, 2017.

[24] A. V. Tyurnina, H. Okuno, P. Pochet, and J. Dijon, "CVD graphene recrystallization as a new route to tune graphene structure and properties," Carbon, vol. 102, pp. 499-505, 2016.

[25] B. Tang, H. Gao, and G. Hu, "Growth mechanism and influences from kinetic factors on carbon materials with $\mathrm{Cu}$ and silica substrates during atmospheric pressure chemical vapor deposition," The Journal of Physical Chemistry C, vol. 117, no. 47, pp. 25175-25184, 2013.

[26] L. Assaud, N. Massonnet, D. Evrard et al., "A new route for the integration of a graphene/diazonium/PEDOT electrode towards antioxidant biomarker detection," Journal of Electroanalytical Chemistry, vol. 771, pp. 73-79, 2016.

[27] G. Deokar, J. Avila, I. Razado-Colambo et al., "Towards high quality CVD graphene growth and transfer," Carbon, vol. 89, pp. 82-92, 2015.

[28] P. Trinsoutrot, C. Rabot, H. Vergnes, A. Delamoreanu, A. Zenasni, and B. Caussat, "High quality graphene synthesized by atmospheric pressure CVD on copper foil," Surface and Coatings Technology, vol. 230, pp. 87-92, 2013.

[29] O. Frank, J. Vejpravova, V. Holy, L. Kavan, and M. Kalbac, "Interaction between graphene and copper substrate: The role of lattice orientation," Carbon, vol. 68, pp. 440-451, 2014.

[30] J.-S. Yu, X. Jin, J. Park et al., "Structural analysis of graphene synthesized by chemical vapor deposition on copper foil using nematic liquid crystal texture," Carbon, vol. 76, pp. 113-122, 2014.

[31] J. Tian, B. Hu, Z. Wei et al., "Surface structure deduced differences of copper foil and film for graphene CVD growth," Applied Surface Science, vol. 300, pp. 73-79, 2014.

[32] R. Jaaniso, T. Kahro, J. Kozlova et al., "Temperature induced inversion of oxygen response in CVD graphene on $\mathrm{SiO} 2$," Sensors and Actuators B: Chemical, vol. 190, pp. 1006-1013, 2014. 
[33] C.-S. Chen and C.-K. Hsieh, "Effects of acetylene flow rate and processing temperature on graphene films grown by thermal chemical vapor deposition," Thin Solid Films, vol. 584, pp. 265269, 2015.

[34] M. Qi, Z. Ren, Y. Jiao et al., "Hydrogen kinetics on scalable graphene growth by atmospheric pressure chemical vapor deposition with acetylene," The Journal of Physical Chemistry C, vol. 117, no. 27, pp. 14348-14353, 2013.

[35] J. Hwang, S. Sasaki, M. Ohnishi et al., "Electronic properties and strain sensitivity of CVD-grown graphene with acetylene signatures for the estimation of defect density electrodes," Japanese Journal of Applied Physics, vol. 55, pp. 04EP05-104EP05-8, 2016.

[36] N. S. Mueller, A. J. Morfa, D. Abou-Ras, V. Oddone, T. Ciuk, and M. Giersig, "Growing graphene on polycrystalline copper foils by ultra-high vacuum chemical vapor deposition," Carbon, vol. 78, pp. 347-355, 2014.

[37] B. Xiao, X.-F. Yu, and Y.-H. Ding, “Theoretical investigation on the healing mechanism of divacancy defect in CNT growth by $\mathrm{C} 2 \mathrm{H} 2$ and C2H4," Journal of Molecular Modeling, vol. 20, no. 3, pp. 640-645, 2014.

[38] A. A. Puretzky, D. B. Geohegan, S. Pannala et al., "Real-time optical diagnostics of graphene growth induced by pulsed chemical vapor deposition," Nanoscale, vol. 5, no. 14, pp. 65076517, 2013.

[39] P. Atkins and J. De Padua, Physical Chemistry, 8th edition, 2006.

[40] J. O. Maloney, Perry's Chemical Engineers' Handbook, United States of America: McGraw-Hill Companies, 8th edition, 2008.

[41] I. N. Levine, Physical Chemistry, 6th edition, 2002.

[42] R. D. Gaskell, Introducction to the Termodynamics of Materials, 5th edition, 2008.

[43] S. D. Costa, A. Righi, C. Fantini et al., "Resonant Raman spectroscopy of graphene grown on copper substrates," Solid State Communications, vol. 152, no. 15, pp. 1317-1320, 2012.

[44] O. I. Aydin, T. Hallam, J. L. Thomassin, M. Mouis, and G. S. Duesberg, "Interface and strain effects on the fabrication of suspended CVD graphene devices," Solid-State Electronics, vol. 108, pp. 75-83, 2015.

[45] C. Melios, A. Centeno, A. Zurutuza et al., "Effects of humidity on the electronic properties of graphene prepared by chemical vapour deposition," Carbon, vol. 103, pp. 273-280, 2016.

[46] K. Gajewski, S. Goniszewski, A. Szumska et al., "Raman Spectroscopy and Kelvin Probe Force Microscopy characteristics of the CVD suspended graphene," Diamond and Related Materials, vol. 64, pp. 27-33, 2016.

[47] S. Tian, Y. Yang, Z. Liu et al., "Temperature-dependent Raman investigation on suspended graphene: Contribution from thermal expansion coefficient mismatch between graphene and substrate," Carbon, vol. 104, pp. 27-32, 2016.

[48] A. C. Ferrari, J. C. Meyer, V. Scardaci et al., "Raman spectrum of graphene and graphene layers," Physical Review Letters, vol. 97, no. 18, pp. 1-4, 2006.

[49] L. M. Malard, M. A. Pimenta, G. Dresselhaus, and M. S. Dresselhaus, "Raman spectroscopy in graphene," Physics Reports, vol. 473, pp. 51-87, 2009.

[50] J. Han, J.-Y. Lee, and J.-S. Yeo, "Large-area layer-by-layer controlled and fully bernal stacked synthesis of graphene," Carbon, vol. 105, pp. 205-213, 2016.

[51] R. K. de Castro, J. R. Araujo, R. Valaski et al., "New transfer method of CVD-grown graphene using a flexible, transparent and conductive polyaniline-rubber thin film for organic electronic applications," Chemical Engineering Journal, vol. 273, pp. 509-518, 2015.

[52] M.-C. Chuang and W.-Y. Woon, "Nucleation and growth dynamics of graphene on oxygen exposed copper substrate," Carbon, vol. 103, pp. 384-390, 2016.

[53] S. Chen, H. Ji, H. Chou et al., "Millimeter-size single-crystal graphene by suppressing evaporative loss of $\mathrm{Cu}$ during low pressure chemical vapor deposition," Advanced Materials, vol. 25, no. 14, pp. 2062-2065, 2013.

[54] S. Kim, Y. Song, J. Wright, and M. J. Heller, "Graphene bi- and trilayers produced by a novel aqueous arc discharge process," Carbon, vol. 102, pp. 339-345, 2016. 


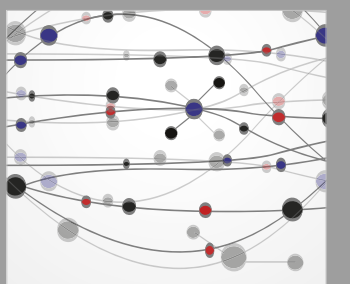

The Scientific World Journal
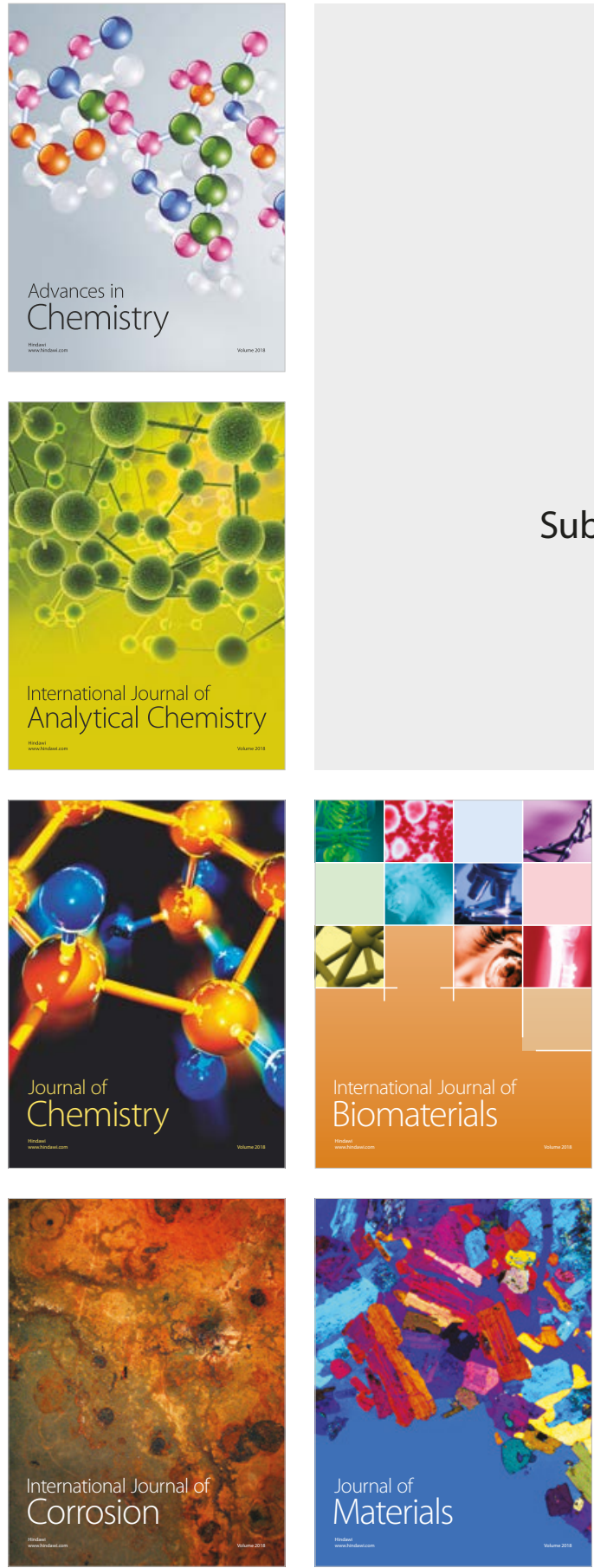

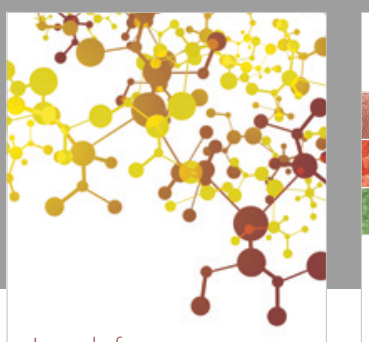

Journal of

Applied Chemistry
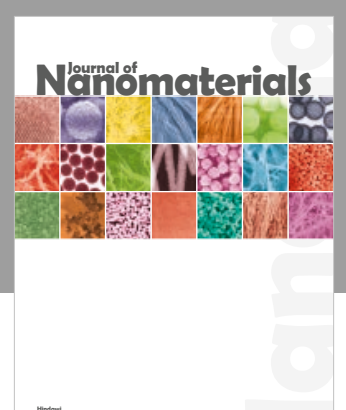

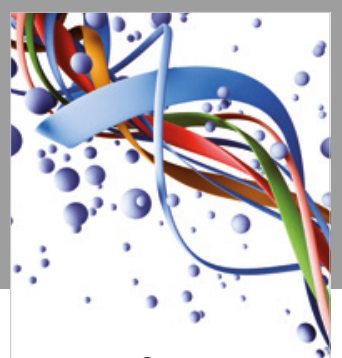

Scientifica

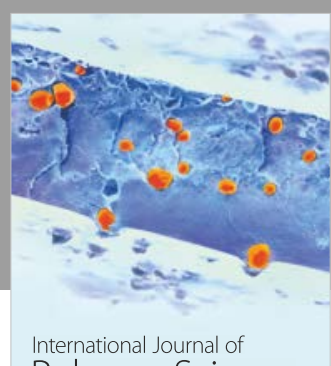

Polymer Science

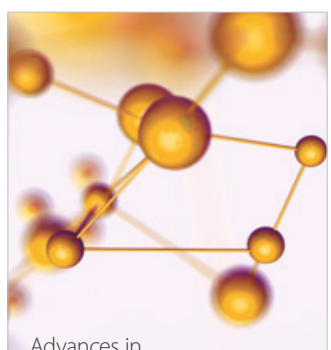

Physical Chemistry
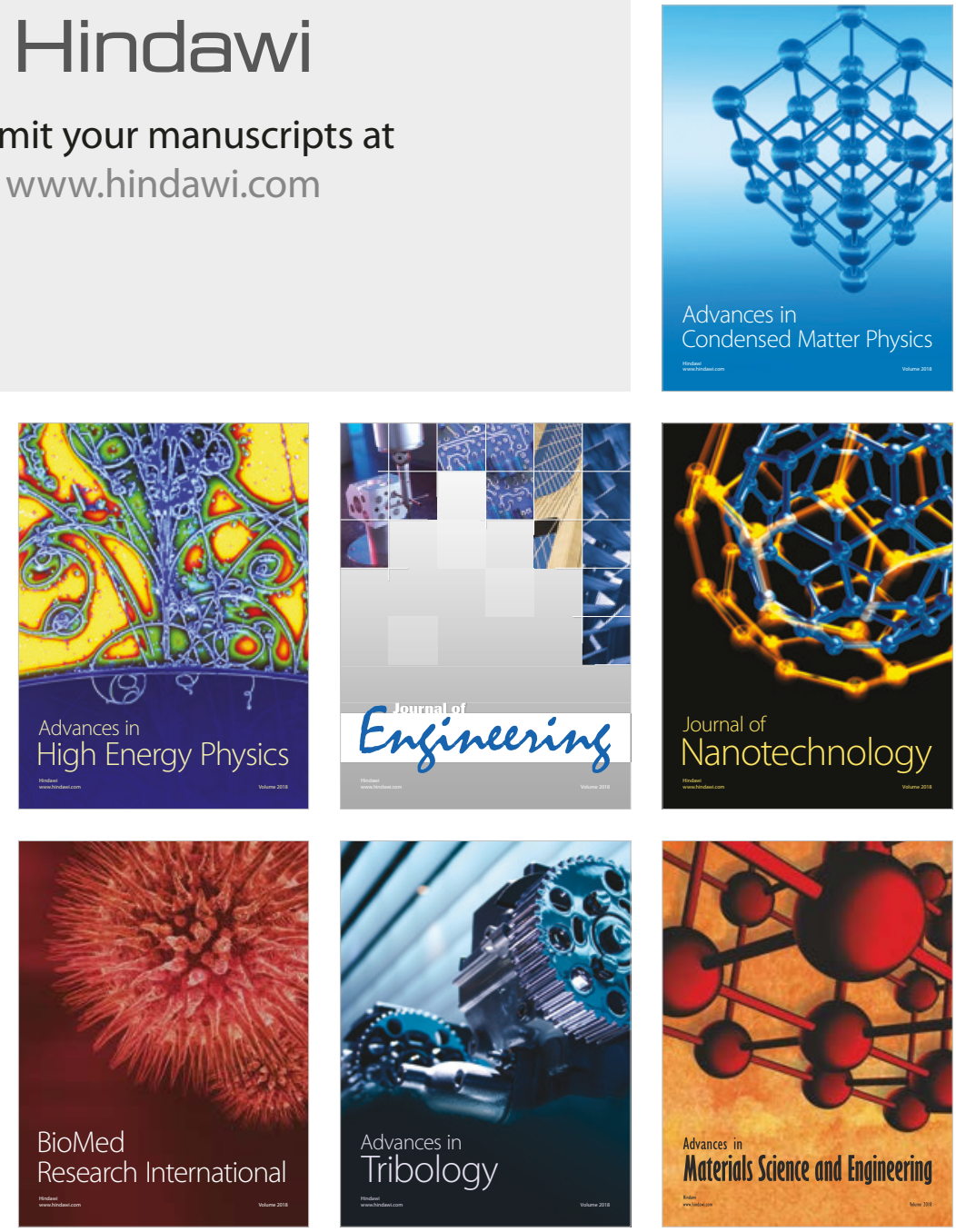